\title{
Resíduo úmido de cervejaria na alimentação de cabras ${ }^{1}$
}

\section{Veridiana Basoni Silva ${ }^{2}$, Carlos Elysio Moreira da Fonseca ${ }^{3}$, Mirton José Frota Morenz ${ }^{4}$, Eduardo Lucas Terra Peixoto ${ }^{5}$, Elisabeth dos Santos Moura ${ }^{5}$, Isabel das Neves Oiticica de Carvalho ${ }^{6}$}

${ }^{1}$ Pesquisa financiada pela Fundação Carlos Chagas Filho de Amparo à Pesquisa do Estado do Rio de Janeiro - FAPERJ.

2 Doutoranda UFMG.

3 Instituto de Zootecnia - Universidade Federal Rural do Rio de Janeiro.

4 Instituto de Veterinária - Universidade Federal Rural do Rio de Janeiro.

5 Graduando do Curso de Zootecnia - UFRRJ.

${ }^{6}$ Mestranda do PPGZ-IZ-UFRRJ.

RESUMO - Objetivou-se avaliar o efeito da substituição do concentrado pelo resíduo úmido de cervejaria sobre o consumo e a digestibilidade dos nutrientes em cabras. Foram utilizadas cinco cabras mestiças Boer $\times$ Saanen e cinco cabras Saanen distribuídas em dois quadrados latinos $5 \times 5$. As dietas foram compostas de $40 \%$ de feno de capim-tifton e os $60 \%$ restantes foram compostos de $0,25,50,75$ ou $100 \%$ de resíduo úmido de cervejaria em substituição ao concentrado. Os consumos de matéria seca (MS), matéria orgânica (MO), proteína bruta (PB), extrato etéreo (EE), carboidratos totais (CT), nutrientes digestíveis totais (NDT) e fibra em detergente neutro (FDN) ajustaram-se ao modelo quadrático, de modo que os maiores valores foram observados para as dietas sem resíduo úmido de cervejaria e com $25 \%$ desse resíduo. Os níveis de resíduo úmido de cervejaria tiveram efeito linear decrescente na digestibilidade aparente de matéria seca, matéria orgânica e carboidratos totais e efeito quadrática na digestibilidade da proteína bruta. O resíduo úmido de cervejaria pode ser utilizado em níveis de até $25 \%$ como substituto ao concentrado em dietas para cabras no final da lactação.

Palavras-chave: bagaço de malte, caprinos, consumo, digestibilidade, resíduos agroindustriais

\section{Wet brewer grains on goat feeding}

\begin{abstract}
The aim of this work was to evaluate the effect of replacing concentrate by wet brewer grain on the intake and digestibility of nutrients in goats. It was used five Boer $\times$ Saanen crossbreed goats and five Saanen goats randomly distributed in two $5 \times 5$ latin squares. The diets were composed of $40 \%$ of Tifton hay and the other $60 \%$ were composed of $0,25,50,75$ or $100 \%$ of wet brewer grain replacing the concentrate. The intake of dry matter (DM), organic matter (OM), crude protein (CP), ether extract (EE), total carbohydrates (TC), total digestible nutrients (TDN) and neutral detergent fiber (NDF) were fitted to the quadratic model so the highest values were observed for diets without wet brewer grain and with $25 \%$ of this residue. The levels of wet brewer grain had a decreasing linear effect on apparent digestibility of dry matter, organic matter, and total carbohydrates and a quadratic effect on crude protein digestibility. Wet brewer grain can be used in levels up to $25 \%$ as a substitute to concentrate in diets for goats at the end of lactation.
\end{abstract}

Key Words: digestibility, goats, industrial wastes, intake, malt trash

\section{Introdução}

Alguns resíduos agroindustriais podem ser usados na alimentação dos animais. No entanto, características alimentares podem ser tanto positivas quanto negativas no que diz respeito à conversão do alimento em produto animal. Para que esses resíduos possam ser utilizados com eficiência na produção animal, dentre outros, é necessário avaliar o consumo, a composição químico-bromatológica e a digestibilidade do alimento.
O resíduo úmido de cervejaria é um subproduto com alto teor proteico, rico em fibra, em detergente neutro (FDN), carboidratos totais (CT) e extrato etéreo (EE) (Geron et al., 2008). Devido ao alto teor de FDN e de água, o resíduo úmido de cervejaria pode ser definido como alimento volumoso, mas com bom conteúdo proteico, podendo ser usado para substituir parte do concentrado e parte do volumoso da dieta.

Segundo Clark et al. (1987), a quantidade de PB e outros nutrientes no resíduo de cervejaria, com exceção do amido, 
são maiores que nos cereais que são usados para a fabricação de cerveja. A quantidade de proteína bruta do resíduo úmido de cervejaria varia de $17 \%$ a $32 \%$ e de FDN, de $55 \%$ a 65\% (West et al., 1994; Costa et al., 1995; Geron et al., 2008). O resíduo úmido de cervejaria pode apresentar variações bromatológicas, com base na vasta gama de ingredientes que podem ser usados na fabricação da cerveja.

O alimento só será aproveitado pelo animal se consumido e digerido em quantidade suficiente para suprir as suas exigências nutricionais. O consumo de matéria seca pelos animais pode ser influenciado por diversos fatores, como: aumento de temperatura ambiental e composição química e física da dieta. Cardoso et al. (1982) avaliaram a produção de leite em vacas alimentadas com silagem de sorgo suplementada com resíduo úmido de cervejaria, e observaram maiores produções de leite para os animais que apresentaram maior consumo da dieta, no caso os animais suplementados com silagem de resíduo úmido de cervejaria. Geron et al. (2007) relataram maiores coeficientes de digestibilidade de MS, PB e EE em vacas alimentadas com inclusão de até $15 \%$ de silagem de resíduo úmido de cervejaria na dieta em comparação à dieta sem resíduo úmido de cervejaria.

Tendo em vista o teor proteico e com intuito de averiguar a possibilidade de substituição de parte do concentrado da dieta de cabras, objetivou-se avaliar o consumo e a digestibilidade aparente de nutrientes em cabras alimentadas com diferentes níveis de resíduo úmido de cervejaria em substituição ao concentrado da dieta.

\section{Material e Métodos}

O experimento foi realizado no Setor de Caprinocultura do Instituto de Zootecnia da UFRRJ.

Foram utilizadas dez cabras no terço final de lactação, a partir de 180 dias de lactação, não gestantes, sendo cinco cabras da raça Saanen com peso médio de 53,0 \pm 9,7 kg e cinco cabras mestiças Boer x Saanen, com peso médio de $51,0 \pm 6,2 \mathrm{~kg}$. As cabras foram distribuídas em dois Quadrados Latinos $5 \times 5$, um deles composto por cabras Saanen e outro por mestiças. Antes do início do experimento os animais foram identificados, pesados e tratados contra ecto e endoparasitos e, posteriormente, confinados em gaiolas para ensaios de metabolismo, providas de comedouro, bebedouro e bandeja para coleta total de fezes disposta sob o piso gradeado.

Os tratamentos consistiram em cinco níveis de substituição do concentrado por resíduo úmido de cervejaria $(0,25,50,75$ e 100\%). Foi utilizada uma relação volumoso:concentrado de 40:60, a dieta foi composta por feno de tifton (Cynodon spp.) como volumoso e o concentrado foi formulado para conter $21 \%$ de PB, de forma a apresentar o mesmo teor de PB do resíduo úmido de cervejaria e que suprisse às exigências nutricionais propostas pelo NRC (1981)

O concentrado foi constituído de $54 \%$ de fubá de milho, $31 \%$ de farelo de soja, $14 \%$ de farelo de trigo e $1 \%$ de mistura mineral. O resíduo úmido de cervejaria utilizado foi oriundo da fábrica de cervejas AMBEV, sendo armazenado em galões de plástico e renovado semanalmente.

As cabras foram alimentadas às $9 \mathrm{e} 15 \mathrm{~h}$, com quantidades que permitiram cerca de $20 \%$ de sobra. Cada período experimental teve duração de quinze dias, sendo dez dias de adaptação à dieta e cinco dias de coleta de amostras. As amostras de alimentos e sobras dos alimentos foram coletadas do $11^{\mathrm{O}}$ ao $15^{\mathrm{O}}$ dia de cada período experimental e pesadas; amostras compostas foram acondicionadas em sacos plásticos, identificadas e congeladas a $-20^{\circ} \mathrm{C}$ para posteriores análises.

Foram realizadas coletas totais de fezes do $11^{\circ}$ ao $15^{\circ}$ dia de cada período. As fezes foram pesadas e reunidas de maneira a formarem amostras compostas por animal em cada período e armazenadas a $-20^{\circ} \mathrm{C}$ até a ocasião do processamento e das análises laboratoriais.

As análises de matéria seca (MS), cinzas, proteína bruta (PB), extrato etéreo (EE) e fibra em detergente neutro (FDN) dos alimentos, das sobras e das fezes (Tabela 1) foram realizadas no Laboratório de Nutrição Animal da UFRRJ conforme AOAC (1990) e Van Soest et al. (1991).

A porcentagem de carboidratos totais (CT) foi obtida pela equação: $\mathrm{CT}=100-(\% \mathrm{~PB}+\% \mathrm{EE}+$ cinzas $)$, e para o cálculo do consumo de nutrientes digestíveis totais (cNDT)

Tabela 1 - Composição dos alimentos e das dietas

\begin{tabular}{|c|c|c|c|c|c|c|}
\hline & \multicolumn{6}{|c|}{ Alimento } \\
\hline & \multicolumn{2}{|c|}{$\begin{array}{l}\text { Resíduo úmido } \\
\text { de cervejaria }\end{array}$} & \multicolumn{2}{|c|}{ Concentrado ${ }^{1}$} & \multicolumn{2}{|c|}{$\begin{array}{c}\text { Feno de } \\
\text { capim-tiftor }\end{array}$} \\
\hline Matéria seca & \multicolumn{2}{|c|}{22,0} & \multicolumn{2}{|c|}{88,0} & \multicolumn{2}{|c|}{80,0} \\
\hline Matéria orgânica & \multicolumn{2}{|c|}{95,9} & \multicolumn{2}{|c|}{96,4} & \multicolumn{2}{|c|}{94,9} \\
\hline Proteína bruta & \multicolumn{2}{|c|}{20,3} & \multicolumn{2}{|c|}{20,1} & \multicolumn{2}{|c|}{5,1} \\
\hline Extrato etéreo & \multicolumn{2}{|c|}{9,9} & \multicolumn{2}{|c|}{3,1} & \multicolumn{2}{|c|}{1,2} \\
\hline \multirow[t]{3}{*}{$\begin{array}{l}\text { Fibra em } \\
\text { detergente neutro }\end{array}$} & \multicolumn{2}{|c|}{58,0} & \multicolumn{2}{|c|}{16,0} & \multicolumn{2}{|c|}{76,0} \\
\hline & & \multicolumn{5}{|c|}{$\begin{array}{l}\text { Nível de resíduo úmido } \\
\text { de cervejaria }(\%)\end{array}$} \\
\hline & & 0 & 25 & 50 & 75 & 100 \\
\hline Matéria seca & & 83,2 & 76,6 & 70,0 & 63,4 & 56,8 \\
\hline Matéria orgânica & & 95,5 & 95,4 & 95,4 & 95,5 & 95,5 \\
\hline Proteína bruta & & 11,1 & 11,1 & 11,1 & 11,1 & 11,2 \\
\hline Extrato etéreo & & 1,9 & 2,6 & 3,3 & 4,0 & 4,7 \\
\hline Carboidratos totais & & 81,2 & 80,6 & 80,0 & 79,4 & 78,8 \\
\hline Fibra em detergente & te neutro & 48,9 & 54,0 & 59,1 & 64,2 & 69,3 \\
\hline
\end{tabular}

R. Bras. Zootec., v.39, n.7, p.1595-1599, 2010 
foi utilizada a equação: $\mathrm{cNDT}=\mathrm{CPBd}+2,25 \times \mathrm{CEEd}+\mathrm{CCTd}$, onde CPBd, CEEd e CCTd correspondem, respectivamente, aos consumos de PB digestível, EE digestível e carboidratos totais digestíveis. Ambas as equações foram propostas por Sniffen et al. (1992).

Para observar se os diferentes genótipos influenciariam na resposta, a análise de variância inicialmente foi feita avaliando separadamente os grupos genéticos, em vista da não significância destes nas variáveis estudadas, e os dados posteriormente foram trabalhados em conjunto.

Os resultados foram submetidos a análises de variância e as médias, estudadas por meio de análise de regressão ( $\alpha=0,05)$, utilizando-se o Sistema de Análises Estatísticas -SAEG(UFV, 1999).

\section{Resultados e Discussão}

Os níveis de resíduo úmido de cervejaria tiveram efeito quadrático sobre o consumo de matéria seca (Tabela 2), que aumentou até o nível de $25 \%$ de inclusão desse alimento. Os animais alimentados com dietas contendo níveis de $75 \%$ e $100 \%$ diminuíram o consumo de MS, em razão das diferentes porcentagens de MS das dietas oferecidas. As dietas com $75 \%$ e $100 \%$ de substituição continham respectivamente $63,4 \%$ e $56,8 \%$ de MS, valores baixos quando comparados aos da dieta sem resíduo úmido de cervejaria (83,2\% de MS).

O menor consumo de MS com o aumento da inclusão de resíduo úmido de cervejaria na dieta pode estar relacionado à maior ingestão de água, decorrente da umidade do resíduo (88\%), e ao seu teor de FDN (tabela 1). A redução dos teores de MS nas dietas com altas quantidades de resíduo úmido de cervejaria é um dos fatores limitantes da utilização do resíduo na formulação das dietas. Segundo o NRC (2001), a ingestão de matéria seca tem relação negativa com altos teores de umidade das dietas.

Dietas com 75 e $100 \%$ de inclusão de resíduo úmido de cervejaria continham elevados teores de FDN, o que comprometeu o consumo de MS e nutrientes. Segundo Mertens (1992), o consumo de alimentos pelos ruminantes depende de fatores físicos que atuam pela distensão do aparelho digestivo, causado pela fibra do alimento, fatores esses que desencadeiam sensação de saciedade em animais, limitando o consumo. Por outro lado, a taxa de passagem de alimentos fibrosos tende a ser mais lenta, o que limita seu consumo.

Os consumos de EE e FDN (g/d) se ajustaram ao modelo quadrático, em que os maiores consumos foram observados para as dietas com níveis de $50 \%$ de substituição. Isso ocorreu devido ao aumento das porcentagens de EE e de FDN nas dietas com maiores níveis de resíduo úmido de cervejaria (Tabela 1), no entanto esse crescimento não foi linear devido à alta umidade da dieta, que limitou o consumo de MS e de nutrientes pelos animais.

Comparando os consumos das dietas oferecidas com o preconizado pelo AFRC (1993) e pelo NRC (2007) para cabras com peso, idade e produção de leite similar aos dos animais usados no experimento, observa-se que as ingestões só atenderam as exigências preconizadas por ambos os sistemas para dietas com até $25 \%$ de inclusão de resíduo úmido de cervejaria (Tabela 3 ).

O consumo de PB e de proteína metabolizável foi maior $(\mathrm{P}<0,05)$ para as dietas com níveis de substituição de $25 \%$. Nas dietas com maiores níveis de resíduo úmido de cervejaria houve redução $(\mathrm{P}<0,05)$ do consumo de proteína. No entanto, os consumos observados para as dietas com níveis de substituição de 0 a $75 \%$ de resíduo úmido de cervejaria foram maiores do que os preditos pelos AFRC (1993) e NRC (2007). Para as dietas com 100\% de substituição, a ingestão de PB e de proteína metabolizável (Tabela 3) situou-se entre os valores propostos pelo AFRC (1993) e pelo NRC (2007).

Os consumos de nutrientes digestíveis totais (NDT) atenderam às exigências das cabras até o nível de $75 \%$ de substituição de concentrado por resíduo úmido de cervejaria

Tabela 2 - Consumo de nutrientes das rações com resíduo úmido de cervejaria

\begin{tabular}{|c|c|c|c|c|c|c|c|c|}
\hline & \multicolumn{5}{|c|}{ Resíduo úmido de cervejaria (\%) } & \multirow[b]{2}{*}{$\mathrm{CV}$} & \multirow[b]{2}{*}{$r^{2}$} & \multirow[b]{2}{*}{ Regressão } \\
\hline & 0 & 25 & 50 & 75 & 100 & & & \\
\hline & (g/dia) & & & & & & & \\
\hline Matéria seca & 1603 & 1650 & 1536 & 1308 & 1024 & 26,3 & 0,99 & $\hat{Y}=1610+2.8 X-0,08 X^{2}$ \\
\hline Matéria orgânica & 1521 & 1565 & 1457 & 1238 & 966 & 26,5 & 0,99 & $\hat{\mathrm{Y}}=1520+2,9 \mathrm{X}-0,09 \mathrm{X}^{2}$ \\
\hline Proteína bruta & 258,5 & 267,9 & 241,5 & 182,4 & 130,8 & 35,2 & 0,96 & $\hat{\mathrm{Y}}=262,35+0,404 \mathrm{X}-0,0176 \mathrm{X}^{2}$ \\
\hline Extrato etéreo & 40,11 & 61,74 & 67,25 & 54,43 & 43,29 & 39,3 & 0,86 & $\hat{\mathrm{Y}}=41,57+0,95 \mathrm{X}-0,0096 \mathrm{X}^{2}$ \\
\hline Carboidratos totais & 1203 & 1220 & 1129 & 992 & 781 & 25,4 & 0,99 & $\hat{\mathrm{Y}}=1210+1,2 \mathrm{X}-0,06 \mathrm{X}^{2}$ \\
\hline Fibra em detergente neutro & 697,7 & 857,1 & 883,4 & 873,5 & 773,5 & 22,8 & 0,96 & $\hat{\mathrm{Y}}=704,17+7,009 \mathrm{X}-0,063 \mathrm{X}^{2}$ \\
\hline Nutrientes digestíveis totais & 1218 & 1267 & $\begin{array}{c}1145 \\
(\% \mathrm{PV})\end{array}$ & 892 & 648 & 33,0 & 0,97 & $\hat{Y}=1230+2,1 X-0,08 X^{2}$ \\
\hline Matéria seca & 3,10 & 3,11 & 2,95 & 2,58 & 1,98 & 29,3 & 0,99 & $\hat{Y}=3,11+0,0058 X-0,00017 X^{2}$ \\
\hline Fibra em detergente neutro & 1,38 & 1,66 & 1,69 & 1,72 & 1,50 & 26,7 & 0,96 & $\hat{\mathrm{Y}}=1,38+0,0128 \mathrm{X}-0,0001 \mathrm{X}^{2}$ \\
\hline
\end{tabular}


Tabela 3 - Exigências preditas e consumos observados de matéria seca (MS), nutrientes digestíveis totais (NDT), proteína bruta (PB) e proteína metabolizável em cabras mantidas com dietas contendo resíduo úmido de cervejaria

\begin{tabular}{|c|c|c|c|c|c|}
\hline & \multicolumn{5}{|c|}{ Nível de resíduo úmido de cervejaria $(\%)^{1}$} \\
\hline & 0 & 25 & 50 & 75 & 100 \\
\hline & \multicolumn{5}{|c|}{ Consumo de MS (kg/dia) } \\
\hline Observado & 1,60 & 1,65 & 1,53 & 1,30 & 1,00 \\
\hline Predito (AFRC, 1993) & 1,56 & 1,45 & 1,47 & 1,44 & 1,46 \\
\hline \multirow{2}{*}{ Predito (NRC, 2007) } & 1,57 & 1,57 & 1,57 & 1,57 & 1,57 \\
\hline & \multicolumn{5}{|c|}{ Nutrientes digestíveis totais ( $\mathrm{kg} / \mathrm{dia})$} \\
\hline Consumo & 1,22 & 1,26 & 1,14 & 0,89 & 0,65 \\
\hline Exigência (AFRC, 1993) & 0,88 & 0,88 & 0,88 & 0,88 & 0,88 \\
\hline \multirow[t]{2}{*}{ Exigência (NRC, 2007) } & 0,83 & 0,83 & 0,83 & 0,83 & 0,83 \\
\hline & \multicolumn{5}{|c|}{ Proteína bruta $(\mathrm{g} / \mathrm{dia})$} \\
\hline Consumo & 258,5 & 267,9 & 241,5 & 182,4 & 130,8 \\
\hline Exigência (AFRC, 1993) & 138,8 & 117,12 & 120,75 & 115,29 & 122,55 \\
\hline \multirow[t]{2}{*}{ Exigência (NRC, 2007) } & 137,0 & 137,0 & 137,0 & 137,0 & 137,0 \\
\hline & \multicolumn{5}{|c|}{ Proteína metabolizável (g/dia) } \\
\hline Consumo $^{2}$ & 173,19 & 179,49 & 161,47 & 122,21 & 87,63 \\
\hline Exigência (AFRC, 1993) & 92,99 & 78,47 & 80,90 & 77,27 & 82,11 \\
\hline Exigência (NRC, 2007) & 97,00 & 97,00 & 97,00 & 97,00 & 97,00 \\
\hline
\end{tabular}

${ }^{1}$ Resíduo úmido de cervejaria; ${ }^{2} \mathrm{~PB}=\mathrm{PM} \div 0,67$ (Valadares Filho, 1999).

(Tabela 3), que, apesar do consumo de MS abaixo de $1,47 \mathrm{~kg}$ preditos pelo AFRC (1993), houve consumo de $892 \mathrm{~g}$ de NDT, valor próximo aos 880 e $830 \mathrm{~g}$ preconizados, respectivamente, pelo AFRC (1993) e NRC (2007). Pode-se inferir que a limitação no consumo de matéria seca influenciou negativamente o consumo dos nutrientes da dieta.

As digestibilidades aparentes de matéria seca, matéria orgânica e carboidratos totais (Tabela 4) apresentaram resposta linear negativa com o aumento da inclusão de resíduo úmido de cervejaria na dieta. Para as dietas sem a adição e com $25 \%$ de resíduo úmido de cervejaria foram observados valores de coeficiente de digestibilidade da MS próximos. As demais dietas com resíduo úmido de cervejaria apresentaram declínio da digestibilidade com aumento das porcentagens do resíduo em sua composição. Derivando a equação de regressão da digestibilidade da MS, obtivemos que o nível ótimo de substituição do concentrado pelo resíduo úmido de cervejaria seria de $16,25 \%$.

Esse fato relaciona-se com a pouca capacidade de aproveitamento do resíduo úmido de cervejaria pelos animais que o consumiram ou a baixa digestibilidade destes.
Processos industriais, como aumento de temperatura e submissão do produto a agentes biológicos e químicos, podem contribuir para uma diferença na qualidade do subproduto, prejudicando as características nutricionais do alimento. Apesar de não avaliado no presente trabalho, pelos resultados pode-se inferir que a qualidade e a quantidade dos carboidratos solúveis do resíduo são inferiores às do concentrado comparado e substituído na dieta.

Considerando que as dietas foram formuladas de forma a possuírem a mesma quantidade de PB (em torno de $11 \%$ PB), a variação da digestibilidade entre as dietas resultou da natureza da proteína contida no resíduo úmido de cervejaria. Aproximadamente $50 \%$ da proteína do resíduo úmido de cervejaria pode estar em forma de proteína não degradável no rúmen (Merchen et al., 1979; Santos et al., 1984; Geron et al., 2007), demonstrando que parcela da proteína do resíduo chega ao intestino delgado e não está disponível para os microrganismos ruminais. Tal fato pode ter prejudicado a manutenção da população microbiana e, consequentemente, o consumo e a digestibilidade dos nutrientes em dietas com mais de $50 \%$ de

Tabela 4 - Coeficientes de digestibilidade total dos nutrientes das rações com resíduo úmido de cervejaria

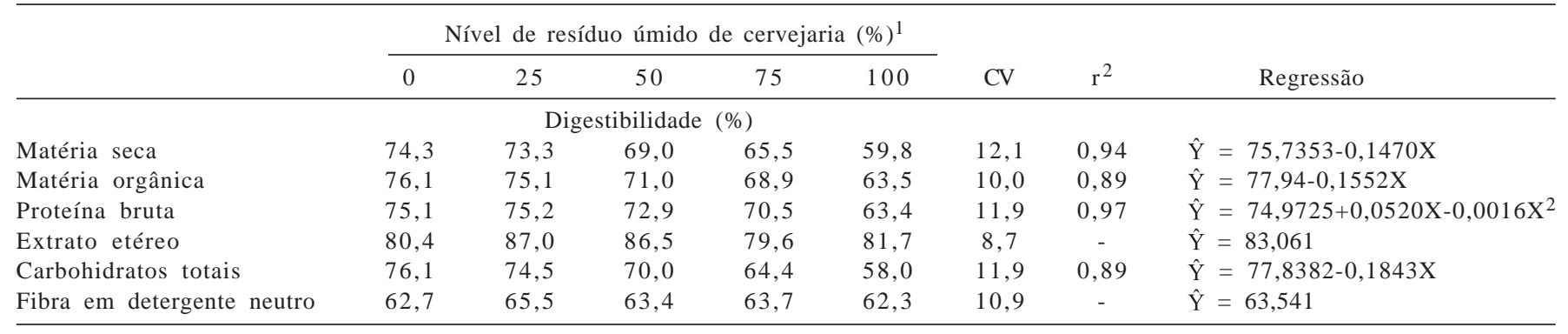


inclusão de resíduo úmido de cervejaria em substituição ao concentrado.

Além da qualidade da proteína, a má qualidade do feno e a baixa quantidade de carboidratos solúveis no resíduo úmido de cervejaria levaram à deficiência energética, que também pode ter prejudicado o desenvolvimento dos microrganismos ruminais, contribuindo para menor digestibilidade e menor consumo das dietas com $100 \%$ de inclusão de resíduo úmido de cervejaria em substituição ao concentrado.

Observou-se que o resíduo úmido de cervejaria é um resíduo com quantidades significativas de proteína, no entanto a sua utilização como principal fonte desse nutriente pode não resultar em produção e resposta favorável por parte dos animais. Isso pode ser corroborado na avaliação do consumo e da digestibilidade das dietas com diferentes inclusões do resíduo, em que as dietas sem inclusão de resíduo úmido de cervejaria e com $25 \%$ de resíduo úmido de cervejaria em substituição ao concentrado foram mais ingeridas e digestíveis do que as demais.

\section{Conclusões}

Em dietas com relação volumoso:concentrado de 40:60 para cabras em final de lactação e em mantença, a utilização de resíduo úmido de cervejaria pode ser feita em níveis de até $25 \%$ em substituição ao concentrado.

\section{Referências}

AGRICULTURAL AND FOOD RESEARCH COUNCIL - AFRC (Technical Committee on Responses to Nutrients). Energy and protein requirements of ruminants. Wallingford: $C A B$ International, 1993. 159p.

ASSOCIATION OF OFFICIAL ANALYTICAL CHEMISTRY A.O.A.C. Official methods of analysis. Washington D.C., 1984. $1141 \mathrm{p}$

CARDOSO, R.M.; SILVA, J.F.C.; MELLO, R.P. et al. Produção de leite de vacas alimentadas com silagem de sorgo suplementada com polpa úmida de cevada. Revista da Sociedade Brasileira de Zootecnia, v.11, n.1, p.38-45, 1982.
CLARK, J.H.; MURPHY, M.R.; CROOKER, B.A. Supplying the protein needsoft dairy cattle from by products feeds. Journal of Dairy Science, v.70, n.5, p.1092-1109, 1987.

COSTA, J.M.B.; MATTOS, W.R.S.; BIONDI, P. et al. Degradabilidade ruminal do resíduo úmido de cervejaria. Boletim Indústria Animal, v.52, n.1, p.87-94, 1995.

GERON, L.J.V.; ZEOULA, L.M.; BRANCO, A.F. et al. Caracterização, fracionamento proteico, degradabilidade ruminal e digestibilidade in vitro da matéria seca e proteína bruta do resíduo de cervejaria úmido e fermentado. Acta Scientiarum Animal Science, v.29, n.3, p.291-299, 2007.

GERON, L.J.V.; ZEOULA, L.M.; ERKEL, J.A. et al. Coeficiente de digestibilidade e características ruminais de bovinos alimentados com rações contendo resíduo de cervejaria fermentado. Revista Brasileira de Zootecnia, v.37, n.9, p.1685-1695, 2008

MERCHEN, N.; HANSON, T.; KLOPFENSTEIN, T. Ruminal bypass of brewers dried grains protein. Journal of Animal Science, v.49, n.1, p.192-198, 1979.

MERTENS, D.R. Análise de fibra e sua utilização na avaliação de alimentos e formulações de rações. In: SIMPÓSIO INTERNACIONAL DE RUMINANTES. Anais... Lavras: SBZESAL, 1992. p.188.

NATIONAL RESEARCH COUNCIL - NRC. Nutrient requirements of goats: angora, dairy, and meat goats in temperate and tropical countries. Washington: National Academic Press, 1981. 91p.

NATIONAL RESEARCH COUNCIL - NRC. Nutrient requirements of dairy cattle. 7.ed. Washington: National Academic Press, 2001. $381 \mathrm{p}$

NATIONAL RESEARCH COUNCIL - NRC. Nutrient requirements of small ruminants: sheep, goats, cervids, and new worlds camelids. Washington: National Academic Press, 2007. 384p.

SANTOS, K.A.; STERN, M.D.; SATTER, L.D. Protein degradation in the rumen and amino acid absorption in the small intestin of lactating dairy cattle fed various proteins sources. Journal Animal Science, v.58, n.1, p.244-255, 1984.

SNIFFEN C.J.; O'CONNOR J.D.; VAN SOEST P.J. et al. A net carbohydrate and protein system for evaluating cattle diets: II Carbohydrate and protein availability. Journal of Animal Science, v.70, p.3562-3577, 1992.

UNIVERSIDADE FEDERAL DE VIÇOSA - UFV. SAEG - Sistema de Análises Estatísticas e Genéticas. Versão 8.0. Viçosa, MG: UFV. 1999. 150p.

VALADARES FILHO, S.C. Padrões de alimentação: fundamentos e programas para cálculo de rações. In: SIMPÓSIO DE PRODUÇÃO DE GADO DE CORTE, 1., 1999, Viçosa, MG. Anais... Viçosa, MG, 1999. p.157-178.

VAN SOEST, P.J.; ROBERTSON, J.B.; LEWIS, B.A. Symposium: carbohydrate methodology, metabolism, and nutritional implications in dairy cattle. Journal of Dairy Science, v.74, n.10. p.3583-3597, 1991.

WEST, J.W.; ELY, L.O.; MARTIN, S.A. Wet brewers grains for lactating dairy cows during hot, humid weather. Journal of Dairy Science, v.77, n.1, p.196-204, 1994. 